\title{
Self-esteem and social development according to participation in school sports club
}

\author{
Su-Hyang Son', Young Jun Koํ, Jun-Su Kim³ ${ }^{3, *}$ \\ 'Department of Physical Education, College of Education, Inha University, Incheon, Korea \\ ${ }^{2}$ Major in Sport Service Practice, College of Welfare Convergence, Kangnam University, Yongin, Korea \\ ${ }^{3}$ Department of Sports and Outdoors, College of Bio Convergence, Eulji University, Seongnam, Korea
}

The purpose of this study is to explore the meaning of the middle school sports club and to understand the impact on the self-esteem and social development of middle school students participating in the school sports club. To achieve the purpose of this study, a questionnaire survey was conducted on 450 students by selecting a middle school. Of the 420 collected questionnaires, 399 questionnaires were used as a valid sample. As a result of examining seven areas of self-esteem, self-esteem in five areas excluding domestic ego and personality ego was highest in the group that participated in the league. As a result of examining the difference in social development according to the type of participation in school sports clubs, the league participation group was higher in all five areas. As a result of examining the difference in self-esteem according to the period of participation in school sports clubs, the group participating in the league was high in six areas excluding physical ability, however, it was difficult to see a statistically significant difference. As for the factor related to physical ability, the group with the longest participation period of 13 months or longer was the highest, and there is a statistically significant difference. As a result of examining the difference in social development according to the period of participation in school sports clubs, the group under 6 months was the highest in four areas other than physical activity. Physical activity was highest in the group over 13 months.

Keywords: Sports club, League participation, Self-esteem, Social development, Type of participation, Period of participation

\section{INTRODUCTION}

Physical activity, including sports participation, prevents obesity, diabetes, cardiovascular diseases, and several cancers (Wannamethee and Shaper, 2001; Warburton et al., 2006). Adults with a low socioeconomic status (SEP) are less likely to participate in physical activity and sports than adults with a high SEP (Beenackers et al., 2012; Trost et al., 2002). Pro-social participation programs are important and important for the healthy growth and social development of youth. Pro-social involvement in adolescence means paid jobs, volunteer work, sports, and games. It functions to enable youth to recognize and accept the social norms and moral standards of society, which will bring positive change for youth and, consequently, benefit society as a whole (Cheng et al., 2006).

Providing health education, increasing the availability of sports facilities, lowering facility prices, and improving safety levels can increase sports participation and moderately reduce the absolute income inequality of sports participation (Blok et al., 2018). Living in neighborhoods with a high prevalence of nonsmoking, no sports participation and overweight increased the odds of quitting smoking, quitting sports, and becoming overweight. Neighborhood prevalence of health-related behaviors and overweight appears to be a currently neglected but relevant determinant of changes in health-related behaviors (Blok et al., 2013).

In adolescence, through the setting and achievement of goals based on various changes and experiences of those changes, the body and mind become mature, self-consciousness is established, and the foundation for growth as a healthy member of society can be laid. In reality, adolescent children in Korea have many demands expected from society, school, or home due to the entrance
${ }^{*}$ Corresponding author: Jun-Su Kim (iD https://orcid.org/0000-0002-7078-4926 Department of Sports and Outdoors, College of Bio Convergence, Eulji University, 553 Sanseong-daero, Sujeong-gu, Seongnam 13135, Korea Email: kjskjs777@hanmail.net

Received: April 7, 2021 / Accepted: May 10, 2021
This is an Open Access article distributed under the terms of the Creative Commons Attribution Non-Commercial License (https://creativecommons.org/licenses/by-nc/4.0/) which permits unrestricted non-commercial use, distribution, and reproduction in any medium, provided the original work is properly cited. 
examination-oriented teaching method and living environment. This acts as a considerable stress for adolescents who are undergoing confusing changes inside and outside the body, causing various conflicts, and causing various problem behaviors to be expressed to the outside. School sports clubs pursue the whole-person development of students and provide a good environment for social development as interactions with others can take place actively. It is also expected to help solve various youth problems such as failure to adjust to school or school violence.

This study examines the impact on the self-esteem and social development of students participating in school sports clubs, helps them to spend their adolescence more desirably, and provides data necessary for the operation of school sports clubs in the future.

\section{MATERIALS AND METHODS}

The purpose of this study is to explore the meaning of the middle school sports club and to understand the impact on the self-esteem and sociality of middle school students participating in the school sports club. To achieve the purpose of this study, a ques-

Table 1. Research subjects

\begin{tabular}{llr}
\hline Grade & Gender & No. $(\%)$ \\
\hline 1 & Male & $70(17.5)$ \\
& Female & $75(18.8)$ \\
2 & Male & $62(15.5)$ \\
3 & Female & $58(14.5)$ \\
& Male & $69(17.3)$ \\
Total & Female & $65(16.4)$ \\
\hline
\end{tabular}

Table 2. Classification according to participation $(n=399)$

\begin{tabular}{lc}
\hline Participation & Number \\
\hline No participation in school sports club & 98 \\
Participation in school sports club & \\
General participation & 121 \\
League participation & 180 \\
\hline
\end{tabular}

Table 3. Classification by participation period $(n=399)$

\begin{tabular}{lc}
\hline Participation period & Number \\
\hline No participation in school sports club & 98 \\
Participation in school sports club & \\
6 mo or less & 76 \\
$7-12$ mo & 76 \\
13 mo or more & 149 \\
\hline
\end{tabular}

tionnaire survey was conducted on 450 students by selecting a middle school. Of the 420 collected questionnaires, 399 questionnaires were used as a valid sample, excluding 21 questions that responded insincerely (Table 1). The data in the questionnaire were analyzed using the SPSS Statistics ver. 18.0 (IBM Co., Armonk, NY, USA), and one-way analysis of variance followed by Scheffe posttest was conducted to determine self-esteem and sociality according to the type and duration of participation in school sports clubs. The composition of the questionnaire to find out the difference in self-esteem and social development according to participation in school sports clubs was a total of 74 questions, including three background variables, four independent variables, 49 questions on self-esteem, and 25 questions on social development (Tables 2,3$)$. Table 4 shows the reliability test of the self-esteem test questionnaire. The results of verifying the reliability of the social development test questionnaire are shown in Table 5. This experiment was approved by the Research Ethics Committee from Inha university (2019-176).

\section{RESULTS}

Table 6 is a result of examining whether there is a difference in the development of self-esteem according to the type of participation in school sports clubs of middle school students. Academic-

Table 4. Questionnaire composition and reliability verification result of self-esteem questionnaire

\begin{tabular}{lccc}
\hline Self-esteem & Item & Item number & Reliability \\
\hline Academic and overall ego & 10 & $3,8,16,22,23,33,35,37,44,45$ & 0.876 \\
Friend-related ego & 9 & $(10), 21,29,31,34,38,39,40,46$ & 0.847 \\
The family ego & 6 & $1,4,7,(9), 24,48$ & 0.760 \\
Body appearance ego & 7 & $(12), 18,19,20,27,30,42$ & 0.721 \\
Personality ego & 6 & $(2),(11),(13),(15),(28),(49)$ & 0.716 \\
Physical ego & 6 & $(5), 6,17,(26), 41,43$ & 0.505 \\
Teacher ability ego & 5 & $(14),(25), 32,36,47$ & 0.752
\end{tabular}

The number in parentheses is reverse scored as a negative question.

Table 5. Social development questionnaire item composition and reliability verification result

\begin{tabular}{lccc}
\hline Social development & Item & Item number & Reliability \\
\hline Activity & 5 & $1,2,(3) .4,5$ & 0.471 \\
Achievement & 5 & $6,7,8,9,10$ & 0.731 \\
Dominance & 5 & $11,12,13,14,15$ & 0.739 \\
Sociability & 5 & $(16), 17,18,19,20$ & 0.642 \\
Autonomy & 5 & $21,22,23,(24),(25)$ & 0.489 \\
\hline
\end{tabular}

The number in parentheses is reverse scored as a negative question. 
Table 6. Verification of differences between groups on self-esteem according to the type of school sports club participation

\begin{tabular}{lcccc}
\hline Factor & $\begin{array}{c}\text { League } \\
\text { participation }\end{array}$ & $\begin{array}{c}\text { General } \\
\text { participation }\end{array}$ & $\begin{array}{c}\text { No } \\
\text { participation }\end{array}$ & $F$ \\
\hline Academic & $3.42 \pm 0.75$ & $3.18 \pm 0.77$ & $3.08 \pm 0.63$ & $6.434^{*}$ \\
Friend & $3.66 \pm 0.56$ & $3.42 \pm 0.62$ & $3.14 \pm 0.67$ & $19.688^{* *}$ \\
Domestic & $3.55 \pm 0.65$ & $3.51 \pm 0.71$ & $3.37 \pm 0.65$ & 2.082 \\
Body appearance & $3.27 \pm 0.65$ & $2.86 \pm 0.62$ & $2.84 \pm 0.68$ & $17.568^{* * *}$ \\
Personality & $2.94 \pm 0.80$ & $2.76 \pm 0.79$ & $2.73 \pm 0.83$ & 2.355 \\
Physical ability & $3.08 \pm 0.60$ & $2.83 \pm 0.56$ & $2.61 \pm 0.52$ & $19.371^{* * *}$ \\
Techer ability & $3.32 \pm 0.61$ & $3.08 \pm 0.59$ & $3.10 \pm 0.55$ & $6.976^{* *}$ \\
\hline
\end{tabular}

Values are presented as mean \pm standard deviation.

${ }^{*} P<0.05 .{ }^{*} P<0.005 .{ }^{* * *} P<0.001$.

related ego was high in the order of nonparticipation in club (3.08 \pm 0.63$)$, participation in club $(3.18 \pm 0.77)$, and participation in league $(3.42 \pm 0.75)$. The group participating in the league showed high academic-related self-esteem. Friends-related ego was highest in the order of nonparticipation in club (3.14 \pm 0.67$)$, participation in club $(3.42 \pm 0.62)$, and participation in league $(3.66 \pm 0.56)$. The group participating in the league showed high self-esteem related to friends. There was no significant difference in domestic ego in club nonparticipation $(3.37 \pm 0.65)$, club participation (3.51 \pm 0.71$)$, and league participation $(3.55 \pm 0.65)$. Body appearance ego was high in the order of nonparticipation in club (2.84 \pm 0.68$)$, participation in club $(2.86 \pm 0.62)$, and participation in league $(3.27 \pm 0.65)$. The group participating in the league showed higher self-esteem related to body appearance. There was no significant difference in personality ego in club participation (2.73 \pm 0.83$)$, club participation $(2.76 \pm 0.79)$, and league participation $(2.94 \pm 0.80)$. The physical ability ego was highest in the order of no club participation $(2.61 \pm 0.52)$, club participation (2.86 \pm 0.56 ), and league participation $(3.08 \pm 0.60)$. The group participating in the league showed higher self-esteem related to physical ability. Teacher competency ego was highest in the order of nonparticipation in club (3.10 \pm 0.55$)$, participation in club (3.08 \pm 0.59$)$, and participation in league $(3.32 \pm 0.61)$. The group participating in the league showed higher self-esteem related to teacher ability.

Table 7 is a result of examining whether there is a difference in social development according to the type of participation in school sports clubs of middle school students. The activity factor was highest in the order of club participation $(3.08 \pm 0.59)$, no club participation (3.10 \pm 0.55$)$, and league participation $(3.22 \pm 0.61)$. The group participating in the league showed higher social development in the activity factor. The achievement factor was highest
Table 7. Verification of differences between groups in social development according to the type of participation in school sports clubs

\begin{tabular}{lcccc}
\hline Factor & $\begin{array}{c}\text { League } \\
\text { participation }\end{array}$ & $\begin{array}{c}\text { General } \\
\text { participation }\end{array}$ & $\begin{array}{c}\text { No } \\
\text { participation }\end{array}$ & $F$ \\
\hline Activity & $3.22 \pm 0.61$ & $3.08 \pm 0.59$ & $3.10 \pm 0.55$ & $6.976^{* *}$ \\
Achievement & $3.21 \pm 0.74$ & $2.94 \pm 0.68$ & $2.95 \pm 0.57$ & $6.595^{* *}$ \\
Dominance & $3.24 \pm 0.66$ & $2.93 \pm 0.70$ & $2.93 \pm 0.60$ & $9.341^{* * *}$ \\
Sociability & $3.55 \pm 0.74$ & $3.21 \pm 0.70$ & $3.17 \pm 0.61$ & $10.648^{* * *}$ \\
Autonomy & $3.36 \pm 0.52$ & $3.17 \pm 0.58$ & $3.25 \pm 0.55$ & $4.382^{*}$ \\
\hline
\end{tabular}

Values are presented as mean \pm standard deviation. ${ }^{*} P<0.05 .{ }^{* *} P<0.005 .{ }^{* *} P<0.001$.

Table 8. Verification of differences between groups on self-esteem according to the period of participation in school sports clubs

\begin{tabular}{lcccc}
\hline Factor & $6 \mathrm{mo}$ or less & $7-12 \mathrm{mo}$ & $13 \mathrm{mo}$ or more & $F$ \\
\hline Academic & $3.22 \pm 0.84$ & $3.15 \pm 0.82$ & $3.36 \pm 0.70$ & 2.061 \\
Friend & $3.40 \pm 0.69$ & $3.52 \pm 0.58$ & $3.58 \pm 0.57$ & 2.167 \\
Domestic & $3.46 \pm 0.77$ & $3.57 \pm 0.67$ & $3.53 \pm 0.66$ & 0.486 \\
Body appearance & $3.02 \pm 0.80$ & $2.96 \pm 0.63$ & $3.05 \pm 0.60$ & 0.539 \\
Personality & $2.87 \pm 0.87$ & $2.76 \pm 0.82$ & $2.85 \pm 0.74$ & 0.436 \\
Physical ability & $2.88 \pm 0.57$ & $2.81 \pm 0.53$ & $3.01 \pm 0.61$ & $3.424^{*}$ \\
Teacher ability & $3.05 \pm 0.57$ & $2.97 \pm 0.60$ & $3.14 \pm 0.57$ & 2.230 \\
\hline
\end{tabular}

Values are presented as mean \pm standard deviation. ${ }^{*} P<0.05$.

in the order of club participation (2.94 \pm 0.68$)$, no club participation $(2.95 \pm 0.57)$, and league participation $(3.21 \pm 0.74)$. The group participating in the league showed higher social development in the achievement factor. The dominance factor was highest in the order of no club participation (2.93 \pm 0.60$)$, club participation (2.93 \pm 0.70$)$, and league participation $(3.24 \pm 0.66)$. The group participating in the league showed higher social development in the dominant factor. The sociability factor was in the order of nonparticipation in the club $(3.17 \pm 0.61)$, participation in the club (3.21 \pm 0.70$)$, and participation in the club league $(3.55 \pm 0.74)$. The group participating in the league showed higher social development in the sociability factor. The autonomy factor was highest in the order of club participation $(3.17 \pm 0.58)$, no club participation $(3.25 \pm 0.55)$, and club league participation $(3.36 \pm 0.52)$. The group participating in the league showed higher social development in the autonomy factor.

Table 8 is a result of examining whether there is a difference in self-esteem according to the period of participation in school sports clubs. The academically related ego was higher in the order of 7 months to 12 months $(3.15 \pm 0.82), 6$ months or less $(3.22 \pm$ $0.84)$, and 13 months or longer $(3.36 \pm 0.70)$, but there was no statistically significant difference. Friend-related ego was higher in 
Table 9. Verification of differences between groups on social development according to the period of participation in school sports clubs

\begin{tabular}{lcrcc}
\hline Factor & 6 mo or less & $7-12$ mo & 13 mo or more & $F$ \\
\hline Activity & $3.19 \pm 0.73$ & $3.09 \pm 0.53$ & $3.21 \pm 0.58$ & $6.976^{* *}$ \\
Achievement & $3.16 \pm 0.82$ & $3.02 \pm 0.67$ & $3.01 \pm 0.68$ & $6.595^{* *}$ \\
Dominance & $3.14 \pm 0.83$ & $2.95 \pm 0.65$ & $3.06 \pm 0.65$ & $9.341^{* * *}$ \\
Sociability & $3.54 \pm 0.82$ & $3.20 \pm 0.68$ & $3.32 \pm 0.69$ & $10.648^{* * *}$ \\
Autonomy & $3.39 \pm 0.60$ & $3.13 \pm 0.57$ & $3.23 \pm 0.53$ & $4.382^{*}$ \\
\hline
\end{tabular}

Values are presented as mean \pm standard deviation.

${ }^{*} P<0.05 .{ }^{* *} P<0.005 .{ }^{* *} P<0.001$.

the order of 6 months or less $(3.40 \pm 0.69), 7$ months to 12 months (3.52 \pm 0.58 ), and 13 months or longer (3.58 \pm 0.57$)$, but there was no statistically significant difference. The domestic ego was higher in the order of 6 months or less $(3.46 \pm 0.77), 7$ to 12 months (3.57 \pm 0.67$)$, and 13 months or more $(3.53 \pm 0.66)$, but there was no statistically significant difference. Body appearance ego was higher in the order of 7 months to 12 months $(2.96 \pm 0.63), 6$ months or less $(3.02 \pm 0.80)$, and 13 months or more $(3.05 \pm 0.60)$, but there was no statistically significant difference. Personal ego was higher in the order of 7 months to 12 months $(2.76 \pm 0.82), 6$ months or less $(2.87 \pm 0.87)$, and 13 months or more $(2.85 \pm 0.74)$, but there was no statistically significant difference. The physical ability ego was higher in the order of 7 months to 12 months (2.81 \pm 0.53$), 6$ months or less $(2.88 \pm 0.57)$, and 13 months or more $(3.01 \pm 0.61)$, which showed statistically significant differences. The group that has participated in school sports clubs for more than 13 months showed higher ego of physical ability. The ego related to teacher ability was higher in the order of 7 months to 12 months $(2.97 \pm 0.60), 6$ months or less $(3.05 \pm 0.57)$, and 13 months or longer $(3.14 \pm 0.57)$, but there was no statistically significant difference.

Table 9 below shows the results to find out whether there is a difference in social development according to the period of participation in school sports clubs. The activity factor was high in the order of 7 months to 12 months (3.09 \pm 0.53$), 6$ months or less (3.19 \pm 0.73$)$, and 13 months or more $(3.21 \pm 0.58)$, which showed statistically significant differences. The group that has participated in school sports clubs for more than 13 months showed the highest activity factor. Achievement factor was high in the order of 7 months to 12 months (3.02 \pm 0.67$), 13$ months or more (3.01 \pm $0.68)$, and 6 months or less $(3.16 \pm 0.82)$, which showed statistically significant differences. The group that has participated in school sports clubs for less than 6 months showed the highest achievement factor. The dominant factor was higher in the order of 7 months to 12 months (2.95 \pm 0.65$), 13$ months or more $(3.06 \pm 0.65)$, and 6 months or less $(3.14 \pm 0.83)$, which showed statistically significant differences. The group who participated in school sports clubs for less than 6 months showed the highest dominance factor. The sociability factor was high in the order of 7 months to 12 months $(3.20 \pm 0.68), 13$ months or more $(3.32 \pm$ $0.69)$, and 6 months or less $(3.54 \pm 0.82)$, which showed statistically significant differences. The group who participated in school sports clubs for less than 6 months showed the highest sociality factor. The autonomy factor was high in the order of 7 months to 12 months (3.13 \pm 0.57$), 13$ months or more (3.23 \pm 0.53$)$, and 6 months or less $(3.39 \pm 0.60)$, which showed statistically significant differences. The group that has participated in school sports clubs for less than 6 months showed the highest factor of autonomy.

\section{DISCUSSION}

Past research has shown that youth who participated in pro-social engagement programs tend to have positive self-awareness, more social skills, and less antisocial behavior. Through participation, youth can redefine their relationship with society and maximize their growth potential (Cheng et al., 2006). The main reasons for spinal cord injury athletes who participated in sports after injury were fitness, fun, health, and competition. However, many athletes noted that social aspects and rehabilitation also affected participation in sports (Wu and Williams, 2001).

The environmental characteristics of the built environment, such as proximity to sports facilities, awareness of social safety, and economic factors such as the price level of sports facilities, contribute to explaining the socioeconomic inequality of participation in sports (Beenackers et al., 2011; Kamphuis et al., 2008). In particular, there was an indirect association of increased self-esteem and physical activity by strengthening adult support as the duration of participation in sports increased. Longer club participation increases physical activity as adult support increases, and longer music participation increases teacher support, resulting in less drug use and higher self-esteem. Long-term participation in certain activities can lead to certain types of supportive relationships that can promote youth well-being (Oosterhoff et al., 2017).

School sports clubs, which have been suggested as a solution to youth problems that are currently being dealt with in society, can have a positive effect on health and body by satisfying and creating a healthy culture for the insufficient amount of activity of youth. In particular, in recent years, there is a trend of recommending the school sports club league activities in which the 
winning team is screened by continuously playing games during school sports club activities.

As a result of examining seven areas of self-esteem, self-esteem in five areas excluding domestic ego and personality ego was highest in the group that participated in the league. As a result of examining the difference in social development according to the type of participation in school sports clubs, the league participation group was higher in all five areas. As a result of examining the difference in self-esteem according to the period of participation in school sports clubs, the group participating in the league was high in six areas excluding physical ability, however, there was no statistically significant difference. As a result of examining the difference in social development according to the period of participation in school sports clubs, the group under 6 months was the highest in four areas other than physical activity. Physical activity was highest in the group over 13 months.

Through the results of this study, there should be a study on various sports and various methods of on-campus and off-campus league systems for vitalization of school sports club league activities.

\section{CONFLICT OF INTEREST}

No potential conflict of interest relevant to this article was reported.

\section{ACKNOWLEDGMENTS}

The authors received no financial support for this article.

\section{REFERENCES}

Beenackers MA, Kamphuis CB, Burdorf A, Mackenbach JP, van Lenthe FJ. Sports participation, perceived neighborhood safety, and individu- al cognitions: how do they interact? Int J Behav Nutr Phys Act 2011; 8:76.

Beenackers MA, Kamphuis CB, Giskes K, Brug J, Kunst AE, Burdorf A, van Lenthe FJ. Socioeconomic inequalities in occupational, leisure-time, and transport related physical activity among European adults: a systematic review. Int J Behav Nutr Phys Act 2012;9:116.

Blok DJ, de Vlas SJ, van Empelen P, Richardus JH, van Lenthe FJ. Changes in smoking, sports participation and overweight: does neighborhood prevalence matter? Health Place 2013;23:33-38.

Blok DJ, van Lenthe FJ, de Vlas SJ. The impact of individual and environmental interventions on income inequalities in sports participation: explorations with an agent-based model. Int J Behav Nutr Phys Act 2018;15:107.

Cheng HC, Siu AM, Leung MC. Prosocial involvement as a positive youth development construct: conceptual bases and implications for curriculum development. Int J Adolesc Med Health 2006;18:393-400.

Kamphuis CB, Van Lenthe FJ, Giskes K, Huisman M, Brug J, Mackenbach JP. Socioeconomic status, environmental and individual factors, and sports participation. Med Sci Sports Exerc 2008;40:71-81.

Oosterhoff B, Kaplow JB, Wray-Lake L, Gallagher K. Activity-specific pathways among duration of organized activity involvement, social support, and adolescent well-being: findings from a nationally representative sample. J Adolesc 2017;60:83-93.

Trost SG, Owen N, Bauman AE, Sallis JF, Brown W. Correlates of adults' participation in physical activity: review and update. Med Sci Sports Exerc 2002;34:1996-2001.

Wannamethee SG, Shaper AG. Physical activity in the prevention of cardiovascular disease: an epidemiological perspective. Sports Med 2001; 31:101-114

Warburton DE, Nicol CW, Bredin SS. Health benefits of physical activity: the evidence. CMAJ 2006;174:801-809.

Wu SK, Williams T. Factors influencing sport participation among athletes with spinal cord injury. Med Sci Sports Exerc 2001;33:177-182. 